\title{
Entrepreneurship to Intrapreneurship: Intrapreneurial Behavior at Individual Level in a Sri Lankan Family Business
}

\author{
Kaluarachchi K.A.S.P. \\ Senior Lecturer Department of Management and Organization Studies Faculty of Management \\ and Finance University of Colombo
}

\begin{abstract}
As a contemporary business issue, several researchers have attempted to understand the factors that stimulate the development of intrapreneurship businesses from their initial status of entrepreneurship. Factors such as external environment, organization structure, business strategy, and management activities have been recognized as what mainly affecting the development of intrapreneurship. Major activities related to intrapreneurship include opportunity perception, idea generation, designing a new product or another recombination of resources, persuading management, planning, and organizing. Key behavioral aspects of intrapreneurship hold personal initiative, information search, new thinking, taking charge, and risk taking. Although the existing studies mostly measure the behavioral aspects of intrapreneurship at the organizational level, still there is a lack of research to study the intrapreneurial behavior at individual level of the organization. Towards a competing methodological dimension, this paper integratively used the three alternative conceptual approaches which reflect the intrapreneurial behavior in diverse aspects. In particular, by adopting the case method, multiple data gathering methods, and qualitative data analysis, the paper examined some key intrapreneurship behavioral aspects in particular at the individual level of a medium scale Sri Lankan family business which has illustrated intrapreneurial characteristics to a greater extent. The paper reveals that the leadership at top with the perception of the family business status of the organization has played the initiative role in making it more intrapreneurial with the concept of corporate entrepreneurship.
\end{abstract}

Key words: Entrepreneurship, Intrapreneurship, Corporate entrepreneurship, The Sri Lankan family business

\section{Background and Issue}

\section{INTRODUCTION}

As a contemporary business issue, most recent research on the entrepreneurial behavior of organizations has given enthusiasm to studying intrapreneurship and independent entrepreneurship comparatively. For example; Boma, Stam, and Wennekers (2011) present the results of the first international comparative study of intrapreneurship and independent entrepreneurship. For them, existence of intrapreneurship is about twice a high in high income countries as in low income countries. Intrapreneurship refers to initiatives by employees in organizations to undertake new business activities. Intrapreneurship is related to corporate entrepreneurship but these concepts differ in some ways (Antoncic \& Hirsrich, 2003; Sharma \& Chriman, 1999). Corporate entrepreneurship is defined at the corporate level and refers to a top-down process, where the management strategy is to foster workforce initiatives to innovate and develop new business. In contrast, intrapreneurship relates to the individual 
level and takes the forms of bottom-up and proactive work-related initiatives of individual employees. Pinchot (1987) refers intrapreneurship to 'dreamers that do' hence it is possible to distinguish between 'vision and imagination' and 'preparation and emerging exploitation' of intrapreneurial behaviors.

According to Gamage, Cameron, and Woods (2003), the entrepreneurial models in exiting Sri Lanka are often based on the assumptions of need for achievement (n-Ach) and personality trait theory but they have neglected socio-cultural factors. For these authors entrepreneurial motivations in Sri Lanka is rooted not in a need for individual achievement, but in the conscious or unconscious need to satisfy a sense of social intimacy. They emphasize that social power, social relations, and collectivism create a setting for entrepreneurial motivation in Sri Lanka that drives directly counter to Western ideologies of entrepreneurial motivation. Exploring the developed factors for intrapreneurship in the plantation sector in Sri Lanka, Ikram, Udugama, and Jayasighe-Mudalige (N.A.) imply that estate managers' ability to create an innovative organizational culture and environment is constrained by the rigidities in the organizations hence the 'empowering' leadership style is proposed to counter the obstacles against the intrapreneurial behaviors of the organizations.

Within the existing understanding of the entrepreneurial and intrapreneurial research issues in the Sri Lankan context as highlighted above, a recent visit to a medium scale Sri Lankan family business enterprise gave exposure to study its intrapreneurial characteristics using a systematic way. The leadership at top of the organization with the perception of its family business status seemed playing the initiative role to make it more intrapreneurial within the concept of corporate entrepreneurship (Sections 3 and 4). Thus, the present study was given motivation to examine the role of leadership at top of the organization in making it more intrapreneurial as a medium scale family business in the Sri Lankan context. The paper first introduces about the research background and issue in particular with its motivation to study the intrapreneurial behavior of the selected organization at the individual level as well the theoretical perspective and methods used in the research to accomplish its intended purpose. Then the paper outlines the selected theoretical debates to distinguish the two concepts of entrepreneurship and intrapreneurship, including the selected past research works in the Sri Lankan context. The background information and the detailed analysis of the case are presented in the third section of the paper. The fourth section discusses the findings by linking them with the related literature. Finally, the paper draws some conclusions as its contribution to the practice and future research in particular in the Sri Lankan context.

\section{Theoretical Perspective}

\section{METHODOLOGY}

Towards a competing methodological dimension, the present study integratively used the three alternative conceptual approaches which reflect the intrapreneurial behavior in diverse aspects. The three approaches were reported in Bosma, Stam and Wennekers (2011). The first approach is 'pursuit of entrepreneurial opportunity', which focuses on developing a new product or service, a new geographical market or a new production process in a broader sense (Shane, 2003 cited). The second approach is reported as 'new entry' (citing Lumpkin \& Dess, 1996) which includes entering new markets with new products, entering established markets with new products or entering new markets with established products. Finally, 'new organization creation' (cited Gartner, 1989) which offers a behavioral intrapreneurship with either be innovative or replicative but mostly be linked to 'internal start-up' of a new business. These three approaches were adopted to understand the intrapreneurial behavior of the organization under study in particular to examine such behavior at the individual level. 


\section{RESEARCH STRATEGY}

The case method (Yin, 2003) was used as the vehicle of conducting and presenting this study. A medium scale family-based entrepreneurial business organization (reflecting some intrapreneurial characteristics) whose head office is in Negumbo, Sri Lanka was selected as the case of the present study (Section 3).

\section{Approach to Data Gathering}

The primary data of the study were gathered through direct observations, short-time interviews, obtaining documentary evidence, participative observations, and in-depth interviews (Yin, 2003) to mainly understand both entrepreneurial and intrapreneurial characteristics of the organization. These data gathering techniques were carried out in the Head Office, the factory, and one major sales outlet of the organization. The data gathered from the Head Office were further cross-checked (Yin, 2003) through the documents, interviews, field notes, and observations involved in the data gathering phase in the factory and the sales outlet. The Chairman, Managing Director, Operational Manager, Sales Manager, Accountant, Factory Manager, some factory workers, and some other workers in the factory and the sales outlet were the informants of the study. The monthly reviews and checklists, policy manuals, process charts, brochures, and notices prepared and placed by the organization were used as the documentary evidence of data gathering.

\section{Approach to Data Analysis}

A substantial part of data analysis was completed using qualitative data (Yin, 2003) in particular by examining major intrapreneurial characteristics of the organization at its individual level. In particular, the three alternative conceptual approaches to intrapreneurial behavior reported in Bosma, Stam and Wennekers (2011) were integratively used with 'pursuit of entrepreneurial opportunity', 'new entry', and 'new organization creation' to understand how these three factors to reflect intrapreneurship have behaved in the organization towards making it more intrapreneurial. The data gathered from interview transcripts, field notes (data gathered during the direct and participative observations), and documentary evidence were used for the identification of an intrapreneurial phenomenon (Yin, 2003 ) in the organization. The phenomenon was in particular investigated through the natural data inquiry used as the informants' narratives of the study (Section 3). The case study result were discussed and linked further with the relevant literature used in the paper as the enhancement of theoretical proposition of the study (Section 4).

\section{ENTREPRENEURSHIP TO INTRAPRENEURSHIP}

Intrapreneurship is a special type of entrepreneurship, which holds key behavioral characteristics such as taking initiative, pursuit of opportunity, and some elements of 'newness.' Major activities related intrapreneurship include opportunity perception, idea generation, designing a new product, building internal coalition, persuading management, resource acquisition, planning, and organization. Key behavioral aspects of intrapreneurship are personal initiative, searching active information, out of the box thinking, taking charge, and some degree of risk taking (Crant, 2000; Kanter, 1988; Lumpkin, 2007; Parker \& Collins, 2010; Pinchot, 1985 cited in Bosma, Stam \& Wennekers, 2011). As reported by Bosma, Stam and Wennekers, a large conceptual diversity remains in the literature with respect to the scope of entrepreneurial behavior which to reflect the intrapreneurial characteristics. For the authors, there are at least three (03) alternative conceptual approaches exist to distinguish the concept of intrapreneurship from entrepreneurship. The first is 'pursuit of entrepreneurial opportunity', which focuses on developing a new product or service, a new geographical market or a new production process in a broader sense (cited Shane, 2003). By citing Lumpkin and Dess (1996), the second view is reported as 'new entry' which includes entering new 
markets with new products, entering established markets with new products or entering new markets with established products. Finally, 'new organization creation' (Gartner, 1989 cited) which offers a behavioral intrapreneurship with either be innovative or replicative but mostly be linked to 'internal start-up' of a new business. Thus, within this theoretical debate of distinguishing intrapreneurship from entrepreneurship, this paper intended to examine the role of leadership at top of the Sri Lankan family based entrepreneurial organization under study in making it intrapreneurial in nature.

\section{THE CASE}

Presently employed about 300 employees, this family business enterprise operates as the CALTON Group of Companies (CALGCs) in Negumbo area of the Western Province of Sri Lanka. The Group comprises CALTON Stores, CALTON Sweet House (Pvt) Ltd, CALTON Hyper Market, and C.C.M. Agro. The CALTON Stores was started in 1983 with four employees to sell groceries to both retail and wholesale customers. With the innovative expansion of this grocery business, it now operates as the main distribution agent for the popular multinational products and brands such as Unilever, Nestle, and Coca-cola in the area. After the successful business journey of the CALTON Stores, with the Governmental tax concessionary agreement to develop innovative high-technology oriented bakery productions in Sri Lanka, in 1996, the CALTON Sweet House (Pvt) Ltd was started up to provide fresh and quality food products to the customers. By adding another innovative business to the Group, the CALTON Hyper Market was initiated in 2007. It was to provide building design and decoration facilities to the customers. Recently, the CALTON Group added the C.C.M. Agro as its agricultural business of planting vegetables and fruits using the new technology.

For its successful entrepreneurial business activities, CALGCs were able to receive number of business as well as social awards from the reputed institutions and the Government. In 2005, the CALTON founder/Chairman, Mr. D.S. De Silva was awarded with the "Deshabandhu" honorary name by the Jathika Sammana Upadhi Sarasavi Institute, Sri Lanka. In 2006 islandwide Presidential award series for small and medium scale entrepreneurs in the industrial sector, both the first district and third provincial awards were received by the CALTON Sweet House (Pvt) Ltd. For the excellent social service offered by the chairman of CALGCs, he was offered with a Gold Name by the Mayor of Negumbo city in 2007. In 2008, he was further recognized with his continuous social and religious service and offered him with an honorary name by the Amarapura Maha Sangha Chapter. In the same year, he was awarded with a great name of the entrepreneurial business leader by the Jathika Sammana Upadhi Sarasavi Institute. The Business and Media World Magazine offered him the Excellent Award of Business Productivity, Management, and the Entrepreneurship in 2009. Further in 2011, the CALTON Sweet House (Pvt) Ltd won the Best Small Business Brand Bonze Medal from the Sri Lanka Institute of Marketing (SLIM). This is for its manufacturing and delivery of quality foods to the customers meeting the international standards. Moreover, it has received the certificates of ISO 22000, HACCP, and GMP for its continuous adherence to the improvement of productivity and quality.

\section{Persuit of Entrepreneurial Opportunities}

Since the initial stage of doing business that was in 1983, the chairman of CALGCs has been trying to understand the business environment carefully which largely helped him to do a good business in most of the times. "Doing the known thing" is a main characteristic of a successful business manager. Moreover, changing according to the timely circumstances is another characteristic to a greater extent. The companies have clearly identified their internal business 
environment under the mission, objectives, departments, and the procedures. As the entrepreneurial business leader, the chairman's view is that:

All in the organization should go towards its targets.

This has led to the development of the mission statement of CALGCs which has been stated as:

Bearing leadership in all business activities through a group of satisfied employees in order to go beyond the customers' expectations in a socially responsible manner.

The mission statement has also contributed to derive the following key objectives.

- Provide a better service to the customers

- Satisfy the targets given by the company

- Share knowledge among the company members

- Collect debts on time

- Help achieving the goals of company members through team work

- Achieve company profits continuously

The objectives are accomplished through the lower level employees by the key positions of Chairman, Managing Director, Board of Directors, Operational Manager, Distribution Manager, and the Group Accountant. However, the management treats all employees of the group as its members. The Board of Directors consists of the Chairman, Managing Director, and three other Directors all who are the family members. Hence, CALGCs are said to be a family-based business in Sri Lanka.

The management team highly relies upon the customers as they are the party which brings money to the business. It also relies upon the suppliers as they contribute to ensure the quality of products. The maintenance of regular relationship with suppliers in different aspects including appropriately paying for the purchases from them helped the company to receive the ISO 22000 quality certificate as well. Further, the company has been provided with the Governmental support time to time. For example, CALTON Sweet House (Pvt) Ltd has been given tax concessionaries by the Government in order to start up of its new bakery using the sophisticated technology.

More importantly, the management of CALGCs follows an open-door policy to deal with the employees which helped maintaining a better labor relation environment within the group. It perceives competition not as a threat but as an opportunity to improving quality of the business. This is highly believed by the chairman. The chairman proclaimed this in a way:

Market competition is a must in order to enhance the quality of the organizations.

The chairman giving leadership at top is dedicated to highly emphasize and act on the external environmental forces and their timely changes while responding them appropriately. For example, the new bakery productions have been introduced to the Sri Lankan market using the sophisticated technology which also in order to face the globalized marketplace proactively. Moreover, the accounting activities are performed using the sophisticated software packages. The persuing new entrepreneurial opportunities by leadership of CALGCs are also illustrated by:

- Proactive business functions

- Reserve business profits in other investments

- Employee training 
- Using new methods of management

More importantly, the chairman of CALGCs believes major business ethics which in turn helped him to achieve the success by capitalizing his entrepreneurial opportunities.

- Taking risks in the business

- 'Walk-the-talk'

- Activeness

- Creativity

- Openness

- Honesty

- Positive thinking

- Closer to people

- Time management

- Sharing business experience with others

\section{New Entry Behaviors}

In developing its corporate strategies CALGCs initially do an environmental analysis. It is usually by doing a SWOT analysis. CALTON band name, experienced workers, high product quality, etc. are the some major strengths (S). High rental expenses and yet to reach the ISO 14000 standards by the company are the major weaknesses (W). In future the company will use the franchising method, grow up the customer base, and enter into the localized food market, which are treated as the major business opportunities (0). Moreover, the ongoing competition to the healthy and safety food products in the market, introduction of new environmental laws by the government, increased cost of living of people, and new entrants by other entrepreneurial firms are recognized as some major threats ( $\mathrm{T}$ ) faced by CALGCs. However, the CALTON management team used to develop the corporate strategies by considering the timely changes in the above variables in an appropriate manner. In an interview, this was supported by the Managing Director saying that:

We as a team commit to identify new changes taken place in the market, while responding them in a timely fashion. But it is our understanding that to do the known thing as the business.

In addition to the corporate strategies, business plans are also prepared for the major businesses. For example, separate business plans are prepared for the CALTON Stores, CALTON Sweet House (Pvt) Ltd, CALTON Hyper Market, and the C.C.M. Agro. All these plans and the underlying decisions are highly based upon the CALTON mission. In this effort, the chairman gives priority to achieve the business goals by providing a high quality service to the customers. For him, the controlling function is done by implementing and evaluating the budgets, procedures, and supervisory activities of the business. The Divisional Heads are aware of interests of the Board of Directors in doing changes to the business. It is said to be having a positive feeling in the management team about the planning function. For CALGCs, the planning function helps the company to reduce both cost and risk of doing business in the long run. It helps achieving timely targets, integrating knowledge and assigning tasks to people, securing confidentiality of the business, and building trust and support with the people.

The strategic positioning of the CALTON group is to identify the market opportunities and satisfy them. It is the principle that the group seeks growth opportunities by providing new opportunities to other small-scale entrepreneurial businesses. The chairman depicts a managerial team oriented leadership style through which employees at different levels are 
encouraged to come out with new ideas and suggestions to the business. This leadership style has contributed to maintain the entrepreneurship and management balance in the group.

\section{New Organization Creation}

It is evidenced that the chairman of CALGCs has based on both personal and business practices in doing entrepreneurial planning function since the start up of CALTON Stores in 1983. It is also noteworthy the ability of him to set plans orienting the timely and situational changes. The history of the CALTON group shows the effectiveness of making decisions by bearing the risk. All these are reflected with the daily routines of the chairman as a business leader, which illustrate the early star up of business each day; engage the business until end of the day; face urgent financial needs of the business; highly committed to the business; getting ideas, suggestions, and supports of the family members; base the principle of low profits and high sales; the feeling of need to do a production; use the past experience towards the future decisions; proper associate with the peer businessmen and search necessary business knowledge from them; plan for acting new ideas of business; proceed to the role of production viewing from the role of customer; utilize foreign technology and knowledge of business; prioritize the quality of products; and achieve advantages over competitors. It is the belief of him that the $30 \%$ and $70 \%$ of entrepreneurial characteristics are inborn and experiential of a person. Hence for him, it is the proper balancing of both family and business of an entrepreneur. It is also attracting and winning the customer for the business.

All employees of CALGCs are rewarded for the success in which the following activities are given priority.

- First, employees are appreciated in monthly meetings

- Talented employees are recommended for rewards in quarterly meetings

- The Chairman, Board of Directors, managers, and all employees of the group conduct a get-together annually on 1st of May

- An annual sports event is conducted among members of the group in order to improve their team spirit

The management of CALGCs highly believes that a selected employee to the group should be the most suitable person to the particular position. The selected employees are induced to the company through specified techniques. Moreover, employee knowledge is tested with its application to the job; CALTON outlets are checked for the quality each month; staff uniforms and their presence as well as the staff health are assessed regularly.

Marketing decisions are taken by considering changes in both behavioral patterns of customers and other environmental factors that affect the business. For example, the brand vision of CALTON bakery products has been stated in a way that:

As your friendliest baker we are happy to save you hygienically prepared tasty products with an outstanding service.

The CALTON management has segmented its entrepreneurial market by targeting the groups shown in Figure 01. 


\section{Figure 01: Target customer groups of CALTON}

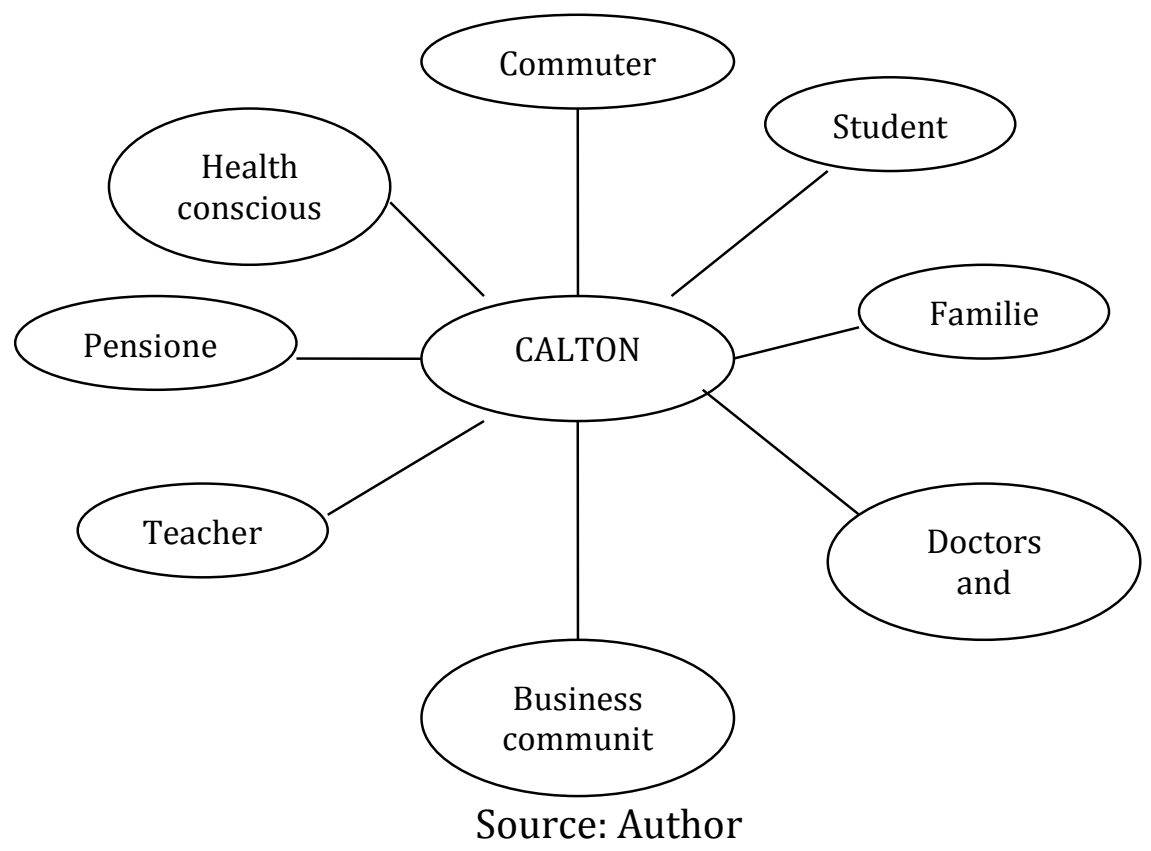

The management has segmented the entrepreneurial market by looking at different types of customer groups and areas affecting the business. The band values of the group are represented by products with quality and customer taste, high customer service, and motivated employees. 'Value for the less price' is the market positioning strategy of products and brands. The management has highly satisfied with the return on investment in the business. With the start up capital of Rs. 6,000/- of the CALTON Stores in 1983, the group has accounted for the net assets of Rs. 46,000,000/- by 2011. Currently, CALGCs are doing business using sophisticated information technology applications, including the internet (www.calton.com) in order to provide a friendly service to the customers. The maintenance of a franchising chain, develop a supermarket network, expand the business into the Free Trade Zones, and satisfy the foreign customers are among its future business plans. With the catalyst role played by the Chairman at top, all these have substantially helped the group to employ its intrapreneurial practices and function as a corporate entrepreneurial entity (Corporate Entrepreneurship) in Sri Lanka.

\section{DISCUSSION}

It is noteworthy the three intrapreneurial approaches which were reported in Bosma, Stam and Wennekers (2011) namely 'pursuit of entrepreneurial opportunity', 'new entry', and 'new organization creation' use here to discuss the role of leadership at top of the Sri Lankan family based entrepreneurial organization under study. The qualitative data analysis of CALGCs illustrated that the catalyst role played by the Chairman at top has substantially helped the group to employ its intrapreneurial practices and function as a successful family based corporate entrepreneurial entity in Sri Lanka. The 'pursuit of entrepreneurial opportunity' was accomplished by the Chairman's new entrepreneurial opportunity search which has been illustrated by his proactive and new management thoughts in intrapreneurial nature. The balancing of both entrepreneurial and management aspects as the top leader with family members and other employees of the organization have greatly contributed to win its 'new entry' behavior in the market. Finally, 'new organization creation' has been illustrated with highly committed employee base and customer service orientation which in turns helped developing a management team based organization with intrapreneurial capabilities. 
According to Gamage, Cameron, and Woods (2003), the existing Sri Lankan entrepreneurial models are often based on the assumptions of need for achievement (n-Ach) and personality trait theory but they have neglected socio-cultural factors. Further, entrepreneurial motivations in Sri Lanka are rooted not in a need for individual achievement, but in the conscious or unconscious need to satisfy a sense of social intimacy. For Ikram, Udugama, and Jayasighe-Mudalige (n.a) an innovative culture and environment to intrapreneurship in Sri Lanka is constrained by the rigidities in the organizations hence the 'empowering' leadership style is proposed to counter the obstacles against the intrapreneurial behaviors of the organizations. The intrapreneurial business achievements of CALGCs and their top leadership seems an exception to the past research arguments in this paragraph.

When it comes to the Sri Lankan context, many efforts of managerial practices in Sri Lankan organizations have experienced the challenge of making different work groups of the organizations corporative to the new improvement efforts they made (Nanayakkara, 1999; Samarathunga \& Bennington, 2002; Gunathunga, 2003; Wickramasinghe \& Hopper, 2005; Wickramasinghe et al., 2004, Opatha, 2001). Moreover, Kaluarachchi $(2009,2010,2011 \mathrm{a}$, 2011b, 2012a, 2012b, 2012c) suggested the importance of the role of democratic leadership of the CEOs as well as the HR leadership to continuous improvement of Sri Lankan organizations. By interconnecting the findings of these past studies, the analysis of CALGCs case illustrated the role of leadership at top of the Sri Lankan family based entrepreneurial organization under study which to successfully integrate the intrapreneurial behaviors showing the concept of corporate entrepreneurship (Section 3).

\section{CONCLUSIONS}

This paper intended to examine the role of leadership at top of the Sri Lankan family based entrepreneurial organization under study which to successfully integrate the intrapreneurial behaviors showing the concept of corporate entrepreneurship. The paper summarizes its concluding remarks using the research findings as follows.

Major activities related to intrapreneurship at CALGCs include, taking risks in the business; 'walk-the-talk'; activeness; creativity; openness; honesty; positive thinking; closure to people; time management; and sharing business experience with others which are more resembled with the behavioral aspects of intrapreneurship (Crant, 2000; Kanter, 1988; Lumpkin, 2007; Parker \& Collins, 2010; Pinchot, 1985 cited in Bosma, Stam \& Wennekers, 2011). The findings lead to interpret the intrapreneurial behavior interconnecting the alternative three approaches: 'pursuit of entrepreneurial opportunity', 'new entry', and 'new organization creation' (Bosma, Stam \& Wennekers, 2011).

The findings of the present study further lead to reinterpret the argument of entrepreneurial motivations in Sri Lanka that is rooted not in a need for individual achievement, but in the conscious or unconscious need to satisfy a sense of social intimacy (Gamage, Cameron, \& Woods, 2003) and interpret the understanding that the ability to create an innovative organizational culture and environment is constrained by the rigidities in the organizations hence the 'empowering' leadership style is proposed to counter the obstacles against the intrapreneurial behaviors of the organizations (Ikram, Udugama, \& Jayasighe-Mudalige (n.a)).

The company being a Sri Lankan organization has functioned as a successful intrapreneurial entity. As a result, the company and its top leadership have been presented with number of awards. The business achievement of the company and its top leadership further interpret and reinterpret the past research findings in the Sri Lankan context (Nanayakkara, 1999; Samarathunga \& Bennington, 2002; Gunathunga, 2003; Wickramasinghe \& Hopper, 2005; 
Wickramasinghe et al., 2004; Opatha, 2001; Kaluarachchi, 2009, 2010, 2011a, 2011b, 2012a, 2012b, 2012c).

The results and findings of this case study could also be helpful for both researchers and managers understand the vital role of effective top business leaders in managing i.e., aligning and engaging people to practicing intrapreneurial activities in order to achieve the success of business in particular in the Sri Lankan context.

To overcome the main limitation of the present study which selected a medium scale Sri Lankan entrepreneurial business as a single case, future studies on the topic need to be carried out as comparative and/or multiple cases or survey research in particular, they may examine the phenomenon in small and large scale entrepreneurial businesses in Sri Lanka.

\section{ACKNOWLEDEGEMENTS}

The author extends his warm gratitude to Masao Yokouchi, Yongdo Kim, and Noriko Taji, the professors attached to the Graduate School of Business Administration of Hosei University, Tokyo. They guided the author as the supporting supervisors during his PhD study (20072011) at the same graduate school. The author offers the special gratitude to the late young scholar, Professor Tomofumi Amano who attached to the Faculty of Economics of the University of Tokyo. Professor Amano guided the author as the academic supervisor during his $\mathrm{PhD}$ study period mentioned above. The author also would like to thank the all study participants of CALGCs, who gave the fullest cooperation during the empirical work of the present study.

\section{References}

Antoncic, B. \& Hisrich, R.D. (2001). Intrapreneurship: construct refinement and cross-cultural validation, Journal of Business Venturing 16, 495-527.

Bosma, N., Stam, E., \& Wennekers, S. (2011). Intrapreneurship versus independent entrepreneurship: A crossnational analysis of individual entrepreneurial behavior. Discussion Paper Series 11-04, Utrecht School of Economics, Jjalling C. Koopmans Research Institute.

Crant, J.M. (2000). Proactive behavior in organizations, Journal of Management 26 (3), 435-462.

Gamage, H.R., Cameron, D., \& Woods, E. (2003). Are Sri Lankan entrepreneurs motivated by the need for achievement? The 9th International Conference on Sri Lanka Studies. University of Ruhuna, Matara, Sri Lanka, 2830 November.

Gunathunge, R.S. (2003). Habermasian way of understanding information systems development in organizations in Sri Lanka. The 9th International Conference on Sri Lanka Studies. University of Ruhuna, Matara, Sri Lanka, 2830 November.

Ikram, S.M.M., Udugama, J.M.M., \& Jayasinghe-Mudalige, U.K. (n.a.). Nurturing intrapreneurship: Exploring the developments in plantation sector in Sri Lanka. www.sljo/info/index.php/JFA/article/download/5171/4123.

Kaluarachchi, K.A.S.P. (2009). Successful TQM implementation in Sri Lankan public hospitals. Annals of Business Administrative Science, 8, Global Business Research Conference, Faculty of Economics, The University of Tokyo, 55-73.

Kaluarachchi, K.A.S.P. (2010). Organizational culture and total quality management practices: A Sri Lankan case. The TQM Journal 21(1), Emerald Group Publishing Limited, U.K., 41-55.

Kaluarachchi, K.A.S.P. (2011a). Moving beyond the metaphoric views of organizational culture to understand the managerial practice: Some critical insights. A paper presented at the Annual Research Symposium, University of Colombo, and June 2011. 
Kaluarachchi, K.A.S.P. (2011b). A democratic leadership to sustain the success of TQM: A case of a Sri Lankan public hospital. A paper presented at the Sixth International Research Conference on Management and Finance, Faculty of Management and Finance, University of Colombo, December 2011, 222-231.

Kaluarachchi, K.A.S.P. (2012a). The role of democratic leadership communication towards organizational performance: The case study of a Sri Lankan public hospital. A paper submitted for the Annual Research Symposium, University of Colombo, and June 2012.

Kaluarachchi, K.A.S.P. (2012b). How democratic type communication mattered to integrated Japanese 5-S based TQM activities in Sri Lankan public hospitals, in H.D. Karunaratne (eds), A journey in harmony: Sixty years of Japan-Sri Lanka relations, Colombo: Faculty of Management and Finance of University of Colombo and Japanese Graduates' Alumni Association of Sri Lanka (JAGAAS), 175-193.

Kaluarachchi, K.A.S.P. (2012c). HR leadership and cohesion of continuous improvement: A case of a Sri Lankan garment factory. A paper presented at the Seventh International Research Conference on Management and Finance, Faculty of Management and Finance, University of Colombo, December 2012, 193-206.

Kanter, R.M. (1988). When a thousand flowers bloom: Structural, collective, and social conditions forinnovation in organization, Research in Organizational Behaviour 10, 169-211.

Lumpkin, G.T. (2007). Intrapreneurship and innovation, in: J.R. Baum, M. Frese \& R. Baron (Eds), the psychology of entrepreneurship, New Jersey: Lawrence Erlbaum Associates, 237-264.

Nanayakkara, G. (1999). Culture and management in Sri Lanka. Colombo: Postgraduate Institute of Management.

Opatha, H.D.N.P. (2001), Politicization and union multiplicity: Two major irritants to good industrial relations in Sri Lanka. Human Resource Management: Interpretive and Explanatory Papers. 1, 10-17.

Parker, S.K. \& Collins, C.G. (2010). Taking stock: Integrating and differentiating multiple proactive behaviors, Journal of Management 36 (3), 633-662.

Pinchot, G. (1987). Innovation through intrapreneuring, Research Management 13 (2), 14-19.

Samarathunga, R. \& Bennington, L. (2002). New public management: Challenge for Sri Lanka. Asian Journal of Public Administration. 24 (3), 87-109.

Sharma, P. \& Chrisman, J.J. (1999). Toward a reconciliation of the definitional issues in the field of corporate entrepreneurship, Entrepreneurship Theory and Practice 23 (3), 11-27.

Wickramasinghe, D.P., Hopper, T., \& Rathnasiri, C. (2004). Japanese cost management meets Sri Lankan politics: Disappearance and reappearance of bureaucratic management controls in a privatized utility. Accounting, Auditing, \& Accountability Journal. 17 (1), 85-120.

Wickramasinghe, D.P. \& Hopper, T. (2005). A cultural political economy of management accounting controls: A case of a textile mill in a traditional Sinhalese village. Critical Perspectives on Accounting. 16, 473-503.

Yin, R.K. (2003). Case study research: Applied social research methods series Vol.5, (3rd ed.), Thousand Oaks, CA: Sage. 